\title{
The influence of body composition
} with acute coronary syndrome: a cohort study

\author{
Fang-Yang Huang ${ }^{1 \dagger}$, Hua Wang ${ }^{1 \dagger}$, Bao-Tao Huang ${ }^{1}$, Wei Liu' ${ }^{1}$, Yong Peng ${ }^{1}$, Chen Zhang ${ }^{1}$, Tian-Li Xia', \\ Peng-Ju Wang ${ }^{1}$, Zhi-Liang Zuo ${ }^{1}$, Yue Heng ${ }^{2}$, Rui-Shuang Liu'², Xiao-Bo Pu' ${ }^{1}$, Yi-Yue Gui ${ }^{1}$, Shi-Jian Chen ${ }^{1}$, Ye Zhu ${ }^{1 *}$ \\ and Mao Chen ${ }^{* *}$
}

\begin{abstract}
Background: Whether body composition is associated with the N-terminal pro-B-type natriuretic peptide (NTproBNP) level and its prognostic performance in acute coronary syndrome (ACS) remains unknown. We aimed to investigate the influence of body composition on the NT-proBNP level and its prognostic performance among ACS patients.

Methods: In total, 1623 ACS patients with NT-proBNP data were enrolled. Percent body fat and lean mass index were estimated using the Clínica Universidad de Navarra-Body Adiposity Estimator equation. Patients were divided into three groups according to the tertiles of sex-specific body mass index, percent body fat, or lean mass index. The endpoints were death from any cause and cardiovascular death.

Results: Body mass index was inversely correlated with NT-proBNP levels $(\beta=-0.036, P=0.003)$. Lean mass index, but not percent body fat, was inversely associated with NT-proBNP levels ( $\beta$ of lean mass index $=-0.692, P=0.002$ ). During a median follow-up of 23 months, 161 all-cause deaths occurred, and of these, 93 (57.8\%) were attributed to cardiovascular causes. Multivariate Cox analysis showed that the NT-proBNP level independently predicted all-cause mortality or cardiovascular death in the lower body mass index, lean mass index, and percent body fat groups. However, the prognostic performance of NT-proBNP was attenuated in patients with high body mass index, lean mass index, and percent body fat. In the subgroup of patients with diabetes, inverse associations between NT-proBNP levels and body mass index or body composition were not observed. In addition, the negative influence of high body mass index and body composition on the prognostic performance of the NT-proBNP level appeared to be attenuated.
\end{abstract}

Conclusions: Body mass index and lean mass index, but not percent body fat, are inversely associated with NTproBNP levels. The prognostic performance of this biomarker may be compromised in patients with high body mass index, percent body fat, or lean mass index. Additionally, the influence of body composition on the NT-proBNP level and its prognostic performance might be attenuated in diabetic patients with ACS.

Keywords: Prognostic performance, N-terminal pro-B-type natriuretic peptide, Acute coronary syndrome, Body composition, Diabetes mellitus

\footnotetext{
*Correspondence: zhuye1974@163.com; hmaochen@vip.sina.com

${ }^{\dagger}$ Fang-Yang Huang and Hua Wang contributed equally to this work

${ }^{1}$ Department of Cardiology, West China Hospital, Sichuan University, 37

Guoxue Street, Chengdu 610041, Sichuan, China

Full list of author information is available at the end of the article
} 


\section{Background}

During the past decade, obesity has become a large public health problem. A previous study reported that the combined prevalence of obesity and overweight has increased by nearly $50 \%$ from 1992 to 2008 in China [1]. A growing number of patients with obesity are at high risk for acute coronary syndrome (ACS) owing to common risk factors, such as diabetes, dyslipidemia, hypertension, and systemic inflammation. N-terminal pro-B type natriuretic peptide (NT-proBNP) is a widely used biomarker, and it has shown robust prognostic potential in ACS [2, 3]. An unexpected inverse relationship between BNP/NT-proBNP levels and body mass index (BMI) has been documented in both healthy individuals and in patients with heart failure [4], and low NTproBNP cut-off levels are recommended in the diagnosis of heart failure among obese patients [5]. However, only two studies have investigated the relationship between the prognostic relevance of NT-proBNP and BMI in ACS patients $[6,7]$, and the findings of these two studies were contradictory. Lorgis et al. [6] suggested that the prognostic performance of NT-proBNP was attenuated in patients with high BMI, while Choi et al. [7] found that the prognostic performance of NT-proBNP was high in patients with high BMI.

BMI does not consider body composition and fat distribution; therefore, the use of BMI as a measure of obesity has been questioned recently $[8,9]$. Body composition considers fat mass and lean mass that includes the muscles, skeleton, and body fluids. Percent body fat (\%BF) and the lean mass index (LMI) have been shown to be more accurate indicators to measure obesity [8, 10]. Additionally, Das et al. [11] showed that natriuretic peptide (NP) levels were better associated with lean mass than with BMI in a healthy population. Nevertheless, the association of body composition with the NT-proBNP level and its prognostic performance in patients with ACS remains unknown. In the present study, we aimed to investigate the influence of body composition on the NTproBNP level and its prognostic performance in patients with ACS. As obesity is generally accompanied with diabetes, we further investigated the influence of body composition on the NT-proBNP level and its prognostic performance in diabetic patients with ACS.

\section{Methods}

\section{Patients}

The present study used data from the West China Hospital coronary artery disease (CAD) database. This database has been described in detail previously [12]. In brief, the database included the data of consecutive patients suspected to have coronary artery disease and those who underwent coronary angiography between July 2008 and September 2012. The database prospectively collected demographic, clinical, laboratory, and treatment data of patients. The inclusion criteria of the present study were as follows: angiographic evidence of $50 \%$ stenosis in $\geq 1$ coronary artery with symptoms, electrocardiography or cardiac biomarker criteria consistent with ACS, presence of complete BMI data, and presence of complete followup information. The study protocol conformed to the ethical guidelines of the 1975 Declaration of Helsinki and was approved by the institutional review board of West China Hospital, Sichuan University (approval number 2012-243). All participants provided informed consent.

\section{Body composition assessment}

During hospitalization, body height and weight of the patients were measured by nurses using standard methods. BMI was calculated as weight $(\mathrm{kg})$ divided by the square of height $\left(\mathrm{m}^{2}\right)$. Body fat (BF) was estimated using the Clínica Universidad de Navarra-Body Adiposity Estimator (CUN-BAE) equation: $\mathrm{BF}=-44.988+(0.50$ $3 \times$ age $)+(10.689 \times$ sex $)+(3.172 \times \mathrm{BMI})-(0.026 \times$ $\left.\mathrm{BMI}^{2}\right)+(0.181 \times \mathrm{BMI} \times$ sex $)-(0.02 \times \mathrm{BMI} \times$ age $)-$ $\left(0.005 \times \mathrm{BMI}^{2} \times\right.$ sex $)+\left(0.00021 \times \mathrm{BMI}^{2} \times\right.$ age $)$, where sex is replaced by 0 for male and 1 for female individuals [13]. This formula has been validated in a large population [14]. The lean mass index was calculated as follows: $(1-\% \mathrm{BF}) \times \mathrm{BMI} \mathrm{kg} / \mathrm{m}^{2}$ [9]. As no reference value has been reported in a Chinese population, we divided the study patients into three groups according to the tertiles of sex-specific BMI, LMI, or BF.

\section{Baseline data collection}

The baseline anthropometric and blood pressure data were collected by nurses. The medical history (history of hypertension, diabetes mellitus, dyslipidemia, heart failure, cerebrovascular accident, and myocardial infarction), smoking history, vital signs at admission, echocardiographic data (left ventricular ejection fraction and left ventricular end-diastolic volume), and final diagnosis were obtained from hospital records and via interviews. In the present study, a patient was considered to have diabetes mellitus if the fasting plasma glucose level, 2-h plasma glucose level after a 75-g oral glucose tolerance test, or hemoglobin A1c level satisfied the ADA criteria at the time of presentation, diabetes was diagnosed by a previous physician, and/or the patient was using insulin or oral hypoglycemic agents. The Killip class and risk stratification of ACS based on the thrombolysis in myocardial infarction (TIMI) risk score for NSTE-ACS or STEMI were evaluated by physicians according to the presentation characteristics. 


\section{Laboratory measurements}

Venous blood samples were collected in tubes containing EDTA and analyzed at the Department of Laboratory Medicine, West China Hospital, accredited by the College of American Pathologists. Plasma NT-proBNP and TnT levels were measured using an electrochemiluminescence immunoassay kit (Roche Diagnostics, Grenzach Wyhlen, Germany). The NT-proBNP results were obtained within the first few days after symptom onset in all of the study patients. The NT-proBNP reference levels in a healthy population depend on age and sex. In male individuals, the 95th percentile level increases from $83.9 \mathrm{pg} / \mathrm{mL}$ at $45-54$ years of age to $486 \mathrm{pg} / \mathrm{mL}$ at $\geq 75$ years of age. In female individuals, the level increases from 169 to $738 \mathrm{pg} / \mathrm{mL}$. The peak plasma TnT level during hospitalization was used in the analysis. The chronic kidney disease epidemiology (CKD-EPI) equation was used to determine the estimated glomerular filtration rate (eGFR).

\section{Endpoint definition and follow-up}

The endpoints were death from any cause and cardiovascular death. Follow-up information was obtained by contacting patients and/or their relatives via letters or the telephone, or through outpatient visits. All data were corroborated with hospital records.

\section{Statistical analysis}

Baseline data are presented as median (with 25th and 75 th percentiles) or counts and proportions. The Chi square test or Fisher's exact test was used to compare categorical variables across different age groups. The Kolmogorov-Smirnov test was used to assess the distribution of the data. If the data followed normal distribution, the data were compared using one-way analysis of variance; otherwise, the data were compared using the Kruskal-Wallis test. Because the NT-proBNP data followed non-normal distribution, the data were logtransformed for multivariate analysis. Considering the presence of right-censored limits of NT-proBNP levels because of the detection threshold $(\leq 35000 \mathrm{pg} / \mathrm{mL})$, a multiple Tobit linear regression analysis was performed to precisely quantify the association between log-transformed NT-proBNP data and other factors. Potential covariates were entered into the model if they had a univariate $\mathrm{P}$ value $<0.10$. To determine the association between NT-proBNP levels and outcomes, KaplanMeier plots by tertiles of NT-proBNP levels were constructed in different body composition strata. Then, Cox proportional hazard analyses were performed to identify the prognostic impact of log NT-proBNP levels stratified according to BMI and body composition. The following variates were included in the multivariate model: age, sex, LVEF, eGFR, Killip >1, TIMI risk score, medical history (previous MI, heart failure, and hypertension) and medications at discharge. The assumption of proportional hazards was assessed on the basis of the methods described by Grambsch and Therneau [15]. Model calibration was evaluated using the Gronnesby and Borgan test [16]. To assess differences between the Cox regression coefficients of NT-proBNP of the body composition strata, the $\mathrm{z}$ test was performed as described previously [17]. All statistical analyses were performed using Stata/ MP 13.0. A two-side P value $<0.05$ was considered statistically significant.

\section{Results}

Of 2251 patients with ACS enrolled into the West China Hospital CAD database, 1623 patients had complete data on NT-proBNP and BMI for analysis in the present study. The baseline characteristics of the patients are shown in Table 1. Age was significantly lower among patients with a high BMI or LMI than among those with a low BMI or LMI. In contrast, age and the number of risk factors for coronary artery disease were significantly higher among patients with a high BF amount than among those with a low BF amount.

The association between NT-proBNP levels and BMI or body composition in the ACS patients is illustrated in Fig. 1. The plasma NT-proBNP levels significantly decreased with the increase in BMI and LMI $(\mathrm{P}=0.001$ and $\mathrm{P}<0.001$, respectively); however, no such decrease was noted with the increase in the $\mathrm{BF}$ amount $(\mathrm{P}=0.608$; Fig. 1). In multivariate Tobit linear regression analysis with only BMI as the measure of obesity in model 1, BMI as a continuous variable was inversely associated with log NT-proBNP levels, and when LMI and BF were added into model 1, only LMI showed an independent inverse correlation with NT-proBNP levels. Additionally, similar results were obtained when BMI, LMI, and BF were considered as categorical variables (Table 2 ).

Over a median follow-up of 23 months (interquartile range, 16-34 months; maximum follow-up, 5.5 years), 161 all-cause deaths occurred, and of these, 93 (57.8\%) were attributed to cardiovascular causes. Kaplan-Meier plots showed that the NT-proBNP tertiles were associated with an increased risk of mortality in all the BMI, LMI, and BF strata (all log-rank P and P for trend $<0.001$ in each group; Fig. 2). In terms of all-cause death, multivariate Cox analysis showed that the NT-proBNP level was an independent predictor of mortality in the 1st and 2nd BMI, LMI, and BF tertiles. However, the prognostic value of the NT-proBNP level was not statistically significant in the high BMI, LMI, and BF groups (Fig. 3). The goodness of fit of the multivariate model was satisfactory $(\mathrm{P}=0.21)$. With regard to cardiovascular death, 


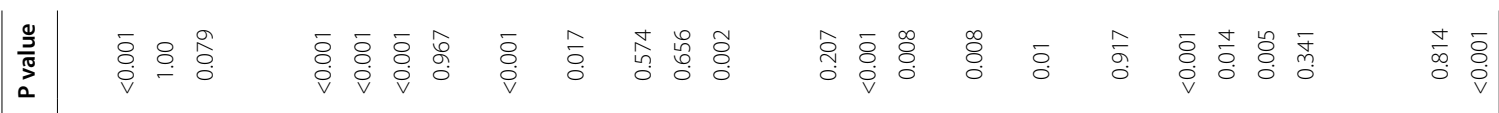

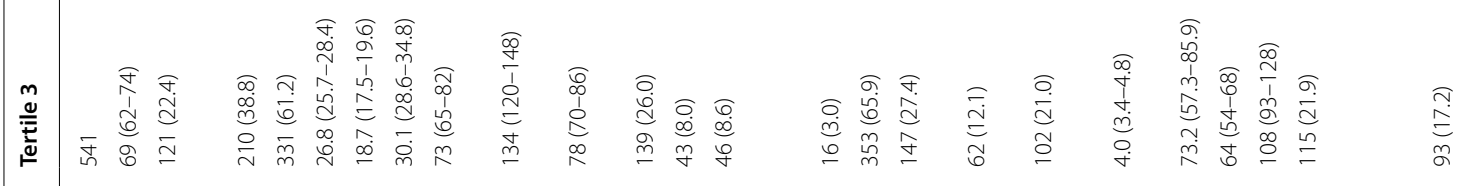

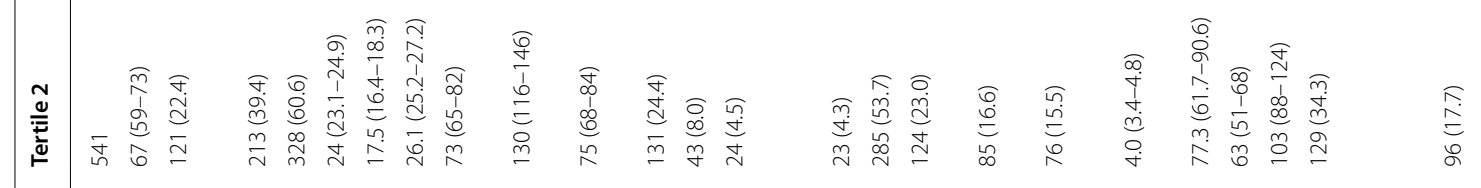

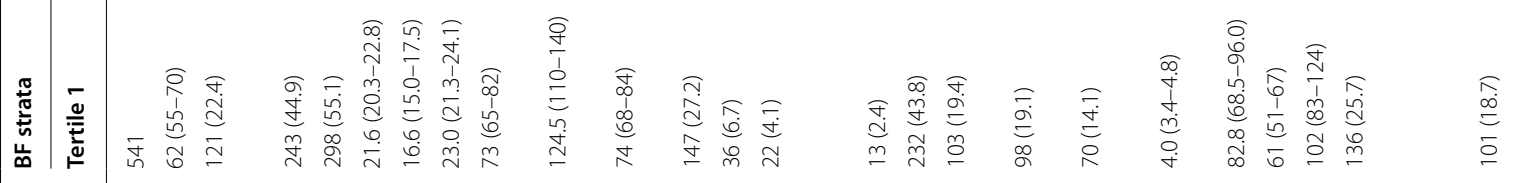

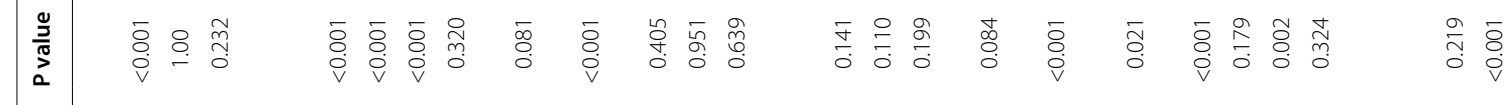

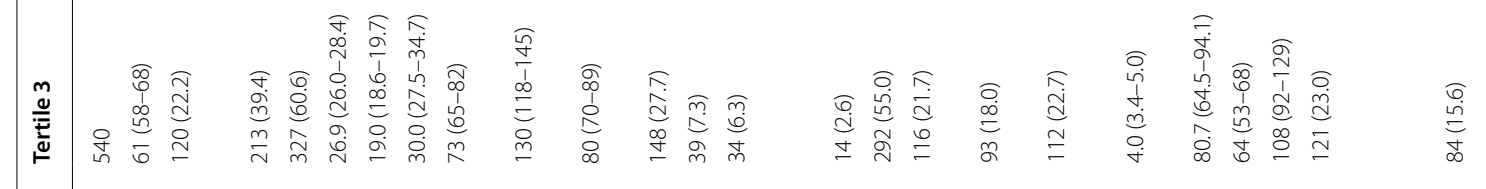

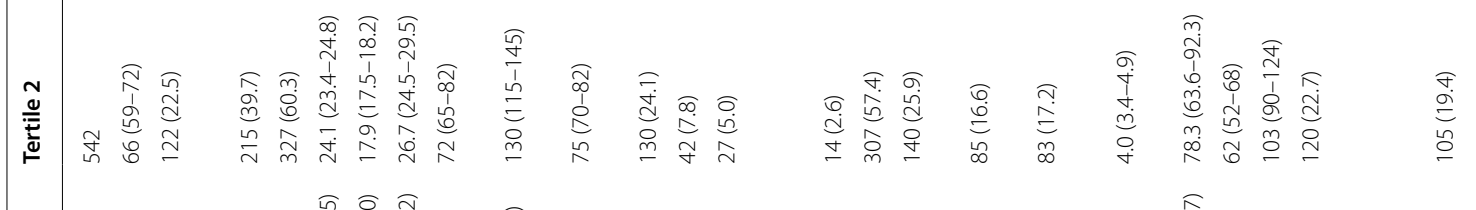

$\overline{0} \overline{0} \overline{0}$

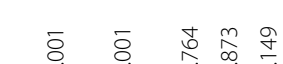

กิกูำ ำำ

$\underset{\infty}{\infty}$

จ.

형 훙 형

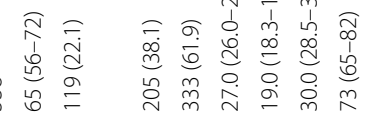

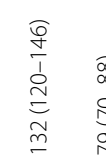

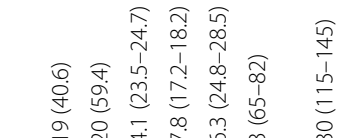

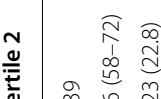
孚

(.) (1)

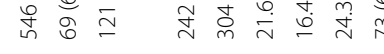

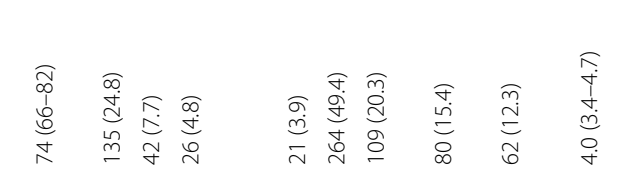

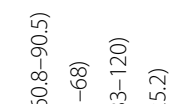

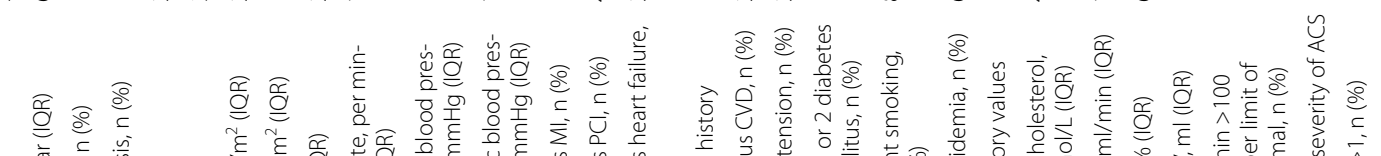

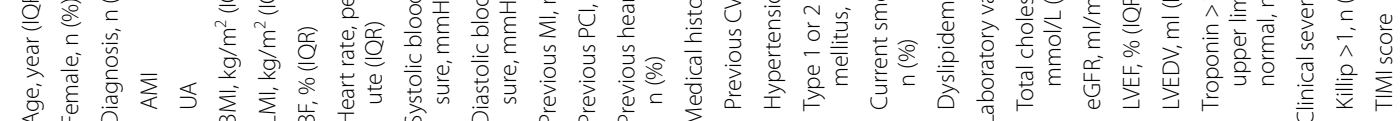




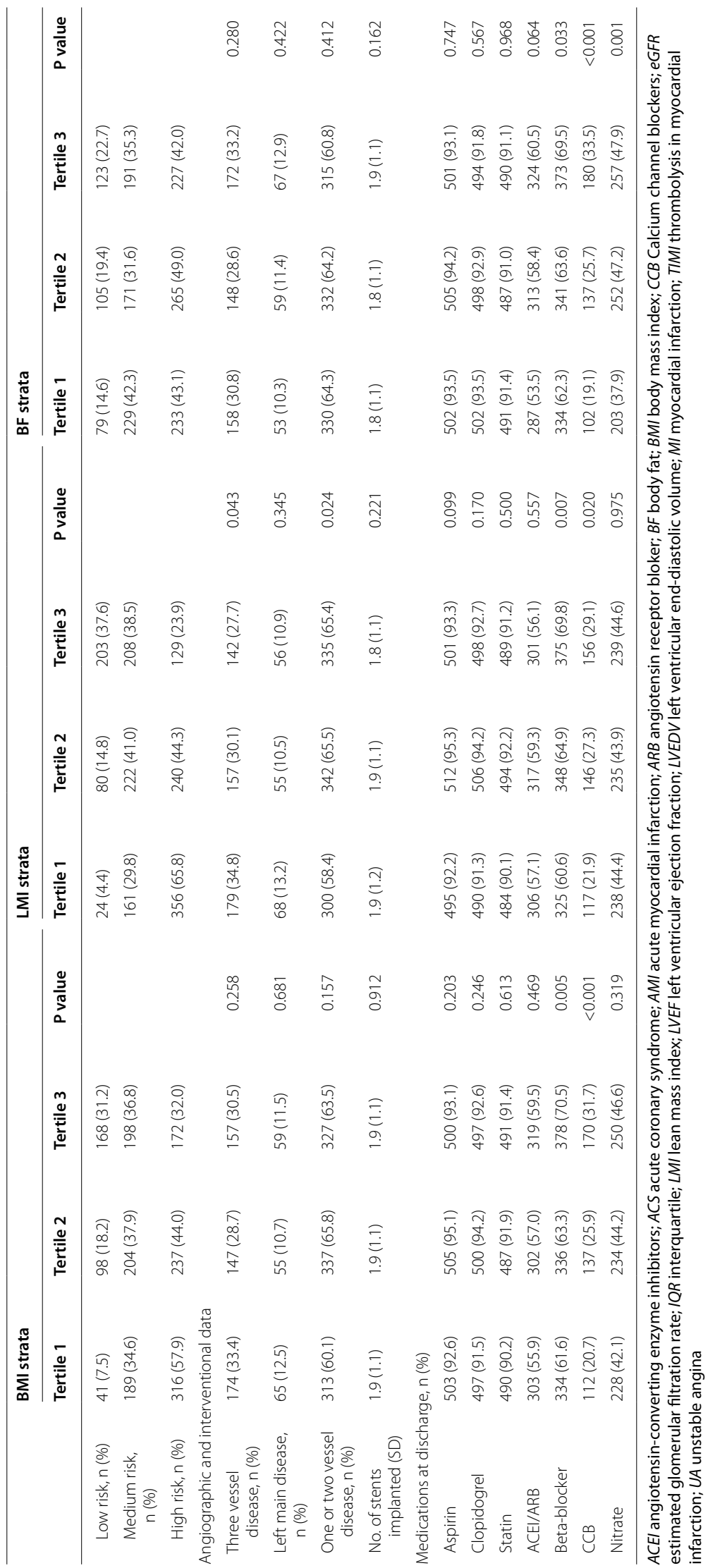



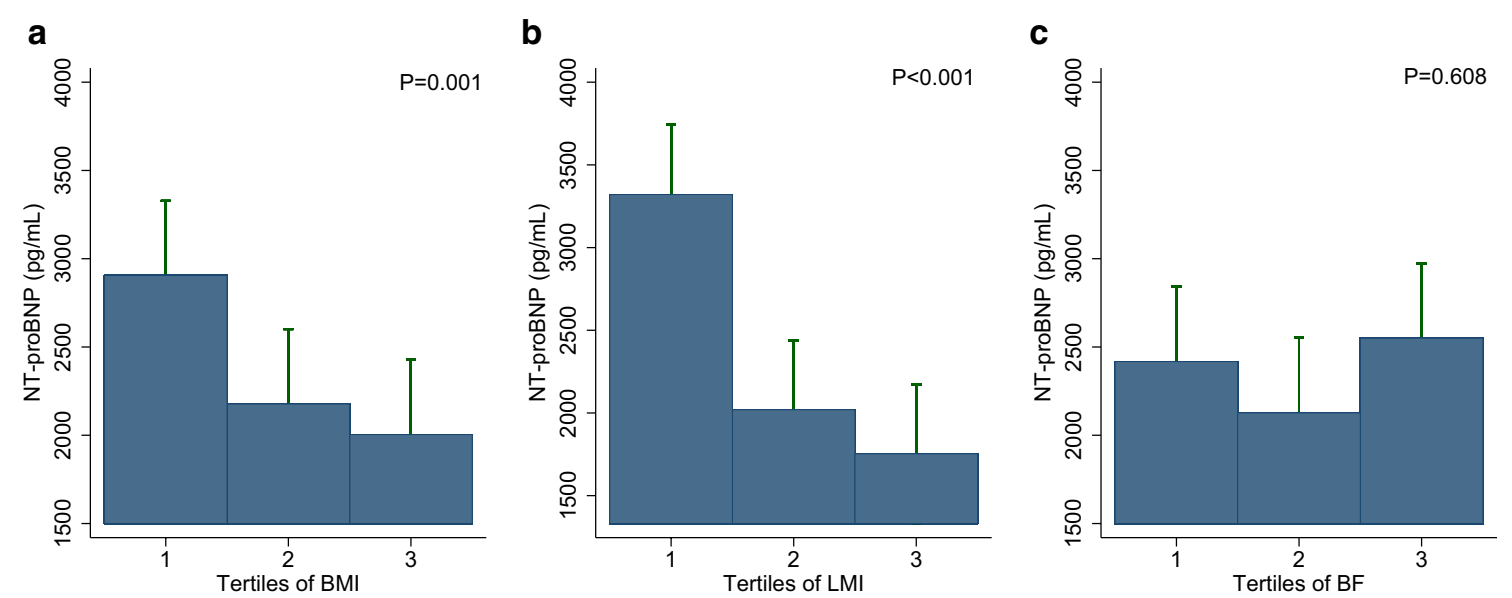

Fig. 1 NT-proBNP levels across the BMI (a), LMI (b), and BF (c) groups. The NT-proBNP levels decreased as the BMI (a) and LMI (b) increased. The NT-proBNP levels did not differ across the BF tertiles (c). NT-proBNP N-terminal-pro B-type natriuretic peptide; BMI body mass index; LMI lean mass index; $B F$ body fat

Table 2 Multivariable Tobit linear regression for Log NTproBNP as dependent variable

\begin{tabular}{|c|c|c|}
\hline & $\beta(\mathrm{SE})$ & $P$ value \\
\hline \multicolumn{3}{|l|}{ Model 1} \\
\hline $\mathrm{BMI}\left(\mathrm{kg} / \mathrm{m}^{2}\right)$ & $-0.036(0.012)$ & 0.003 \\
\hline \multicolumn{3}{|l|}{ Model 2} \\
\hline BMI $\left(\mathrm{kg} / \mathrm{m}^{2}\right)$ & $0.046(0.081)$ & 0.575 \\
\hline $\mathrm{LMI}\left(\mathrm{kg} / \mathrm{m}^{2}\right)$ & $-0.692(0.218)$ & 0.002 \\
\hline $\mathrm{BF}(\%)$ & $0.154(0.091)$ & 0.091 \\
\hline \multicolumn{3}{|l|}{ Model 3} \\
\hline \multicolumn{3}{|l|}{$\mathrm{BMI}$} \\
\hline 2nd BMI tertile & $-0.240(0.089)$ & 0.007 \\
\hline 3rd BMI tertile & $-0.259(0.092)$ & 0.005 \\
\hline \multicolumn{3}{|l|}{ Model 4} \\
\hline \multicolumn{3}{|l|}{ BMI } \\
\hline 2nd BMI tertile & $0.023(0.155)$ & 0.882 \\
\hline 3rd BMI tertile & $0.098(0.236)$ & 0.680 \\
\hline \multicolumn{3}{|l|}{ LMI } \\
\hline 2nd LMI tertile & $-0.384(0.147)$ & 0.009 \\
\hline 3rd LMI tertile & $-0.533(0.213)$ & 0.012 \\
\hline \multicolumn{3}{|l|}{$\mathrm{BF}$} \\
\hline 2nd BF tertile ${ }^{a}$ & $0.024(0.123)$ & 0.845 \\
\hline 3rd BF tertile ${ }^{a}$ & $0.092(0.193)$ & 0.633 \\
\hline \multicolumn{3}{|c|}{$\begin{array}{l}\text { BMI, LMI, and BF are considered as continuous variables in model } 1 \text { and model } 2 \\
\text { and considered as categorical variables in model } 3 \text { and model } 4\end{array}$} \\
\hline \multicolumn{3}{|c|}{$\begin{array}{l}\text { Those models are adjusted for age, sex, LVEF, LVEDV, CKD-EPI, Killip }>1 \text {, heart rate } \\
\text { at admission, AMI, peak troponin, and previous MI }\end{array}$} \\
\hline \multicolumn{3}{|c|}{ Abbreviations as in Table 1} \\
\hline a Reference is the $1 \mathrm{st}$ & & \\
\hline
\end{tabular}

the multivariate Cox analysis showed a significant association between the NT-proBNP level and cardiovascular death among patients with low BMI, LMI, and $\mathrm{BF}$ amount, whereas the association was absent among patients with high BMI, LMI, and BF amount (Fig. 3). The goodness of fit of the multivariate model was satisfactory $(\mathrm{P}=0.61)$, and there was no significant violation of the proportional hazards assumption $(\mathrm{P}=0.12$ for all cause death and $\mathrm{P}=0.06$ for cardiovascular death).

In the subgroup of patients with diabetes, inverse associations between NT-proBNP levels and BMI or body composition were not observed (Fig. 4). In addition, the negative influence of high BMI and body composition on the prognostic performance of the NT-proBNP level appeared to be attenuated (Fig. 5).

\section{Discussion}

The present study found an inverse association between BMI and NT-proBNP levels in patients with ACS. Furthermore, when body composition was considered, LMI, but not BF, was inversely associated with NT-proBNP levels. The prognostic performance of the NT-proBNP level in patients with ACS was compromised among patients with high BMI, LMI, or BF. However, the influence of BMI and body composition on the NT-proBNP level and its prognostic performance appeared to be attenuated in diabetic patients with ACS. To our knowledge, this is the first study to investigate the association between body composition and the prognostic performance of the NT-proBNP level in patients with ACS. 


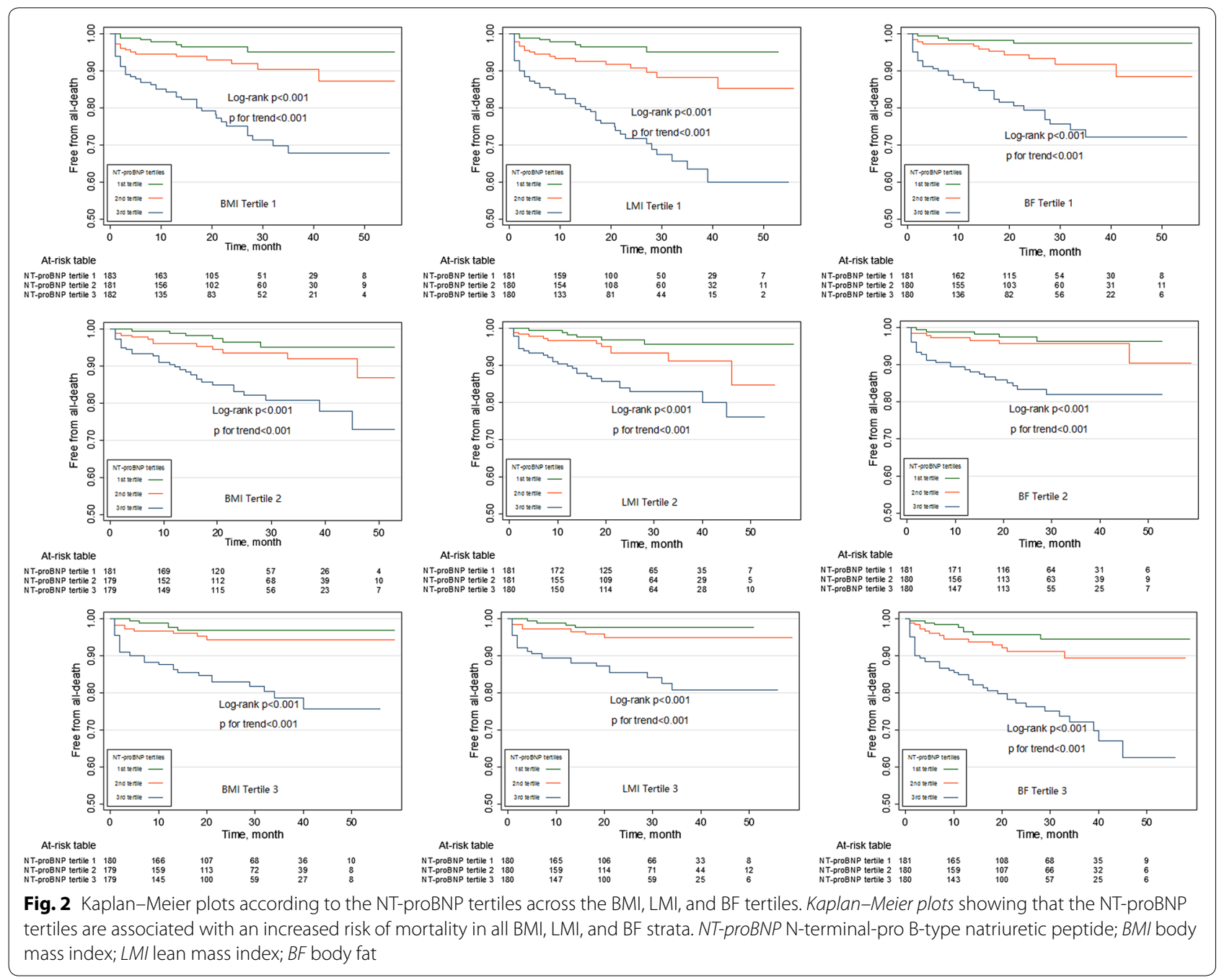

Myocardial ischemia and hypoxia have been shown to directly induce an increase in the expression of proBNP, even in the absence of left ventricular dysfunction [18]. It has been reported that NT-proBNP levels are high across the entire spectrum of CADs and the increase in associated with CAD severity $[19,20]$. Additionally, the angiographic severity of CAD has been shown to be better reflected by the NT-proBNP level than the BNP level [21]. Several studies have validated the prognostic performance of the NT-proBNP level in patients with ACS, which was independent of LVEF, troponin, and renal insufficiency $[2,3]$. Thus, NT-proBNP has been proposed as a promising biomarker for the early diagnosis of ACS [22] and its risk stratification [23-25].

However, the true implications of NT-proBNP in clinical practice were typically influenced by confounders, such as age, sex, diabetes, and renal function. Recently, a study showed that BMI was inversely associated with BNP/NT-proBNP levels [4]. Some of the possible explanations for this phenomenon include an increase in the clearance of natriuretic peptide by the C-type natriuretic peptide receptor [26], impairment of the natriuretic peptide response termed "natriuretic peptide handicap" [27], and compromised detection of NT-proBNP in obese individuals [28]. However, some of these hypotheses have been contradicted [11]. Therefore, the exact mechanism underlying the negative association between NPs and obesity remains undefined. A previous study proposed a bidirectional relationship between BNP and adiposity because BNP has been shown to cause lipolysis via A-type natriuretic peptide receptor [5]. Additionally, Li et al. [29] recently suggested that changes in liraglutide-induced lean mass and body fat were associated with increases in plasma NP levels in obese type 2 diabetic patients. However, our finding that the NT-proBNP levels differ across LMI tertiles, but not BF tertiles, in patients with ACS does not support this hypothesis. In fact, previous studies by Das et al. and 

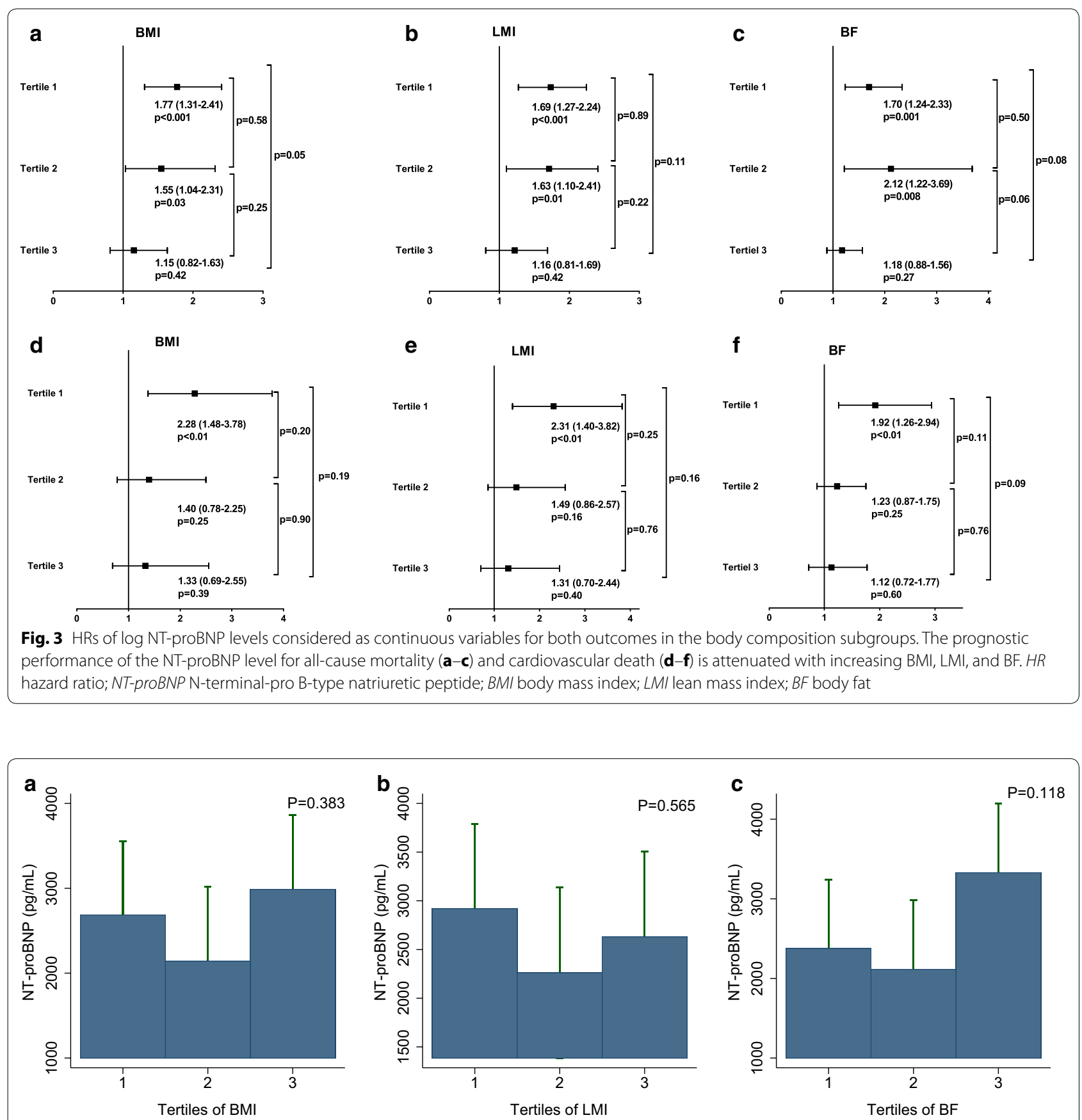

Fig. 4 NT-proBNP levels across the BMI (a), LMI (b), and BF (c) groups among the diabetic subgroups. Inverse associations between NT-proBNP levels and increased BMI or body composition are not observed in the diabetic patients. NT-proBNP N-terminal-pro B-type natriuretic peptide; BMI body mass index; LMI lean mass index; $B F$ body fat

Oreopoulos et al. $[8,11]$ showed that a high LMI, but not BF, was associated with low BNP/NT-proBNP levels in both the general population and a chronic heart failure population. In the present study, these findings were extended to patients with ischemic heart disease. Chang et al. provided a plausible explanation for this finding.
The authors demonstrated that free testosterone was a mediator of the association between lean mass and NPs through an increase in lean mass and a decrease in NP synthesis; however, estradiol, which plays an important role in the regulation of adiposity [30], does not appear to influence NP levels [31]. 


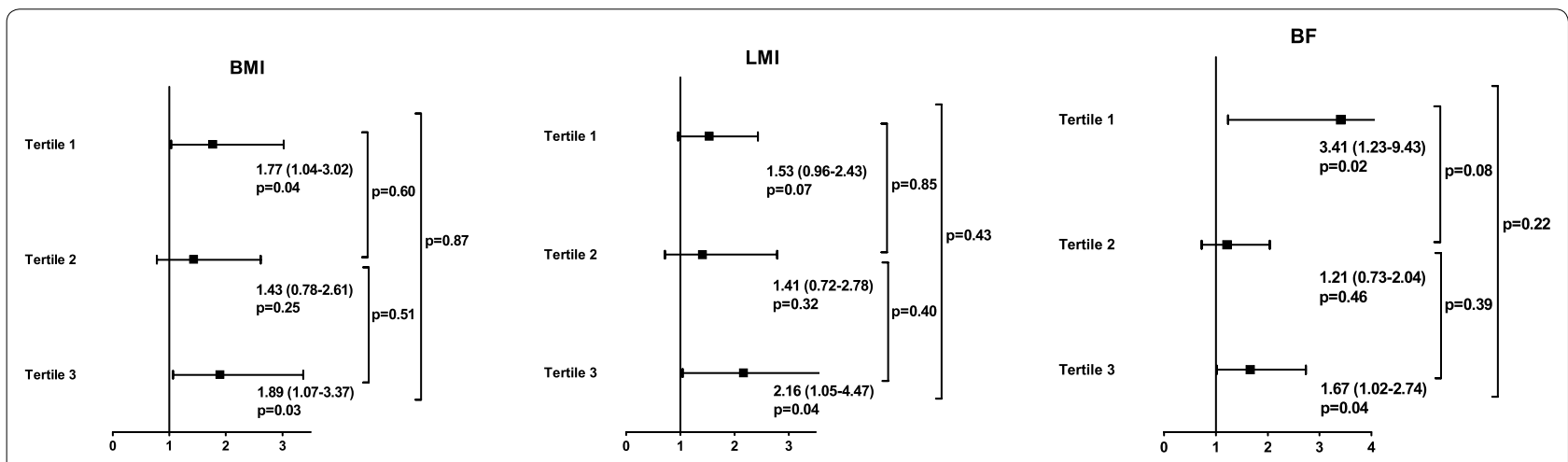

Fig. 5 HRs of log NT-proBNP levels considered as continuous variables for all-cause mortality in the body composition subgroup of diabetic patients. The influence of body composition on the prognostic performance of the NT-proBNP level for mortality is attenuated in the diabetic subgroups. HR hazard ratio; NT-proBNP N-terminal-pro B-type natriuretic peptide; BMI body mass index; LMI lean mass index; BF body fat

Although numerous studies focused on the association between BMI and NT-proBNP levels, few studies have evaluated whether BMI influences the prognostic performance of NT-proBNP in heart diseases, especially ACS. Choi et al. performed a study of 2736 Koreans with acute myocardial infarction (AMI) and showed that NTproBNP levels were lower in obese AMI patients than in non-obese AMI patients and that NT-proBNP was an independent prognostic factor in obese AMI patients. However, it should be pointed out that these authors did not assess the goodness of fit and overall performance of the logistic regression models [7]. Considering that NTproBNP in the multivariate model unreasonably failed to predict outcomes in the normal group $(\mathrm{P}=0.113)$, the calibration of the model was very likely to not be good. Thus, the results were not convincing. On the contrary, Lorgis et al. addressed this issue in a prospective study of 2217 AMI patients. The authors used the WHO BMI classification system to classify the extent of obesity in the patients and showed that log NT-proBNP independently predicted 1-year cardiovascular mortality in normal and overweight patients. However, in obese patients, the propeptide levels failed to retain their prognostic value $(\mathrm{OR}=1.34, \mathrm{P}=0.244)$. The goodness of fit of the final model was good [-2log-likelihood: 642; P (HosmerLemeshow) $=0.479$ ] [6]. Our results from the BMI subgroups extended the findings of the study by Lorgis et al. to the entire spectrum of ACS covering unstable angina.

It is believed that low BNP/NT-proBNP levels are good for prognosis [10]. As obese patients have low BNP/NTproBNP levels, this perspective appears to mirror the obesity paradox in which obesity has a paradoxical survival benefit [32]. However, the paradox has been almost exclusively documented in studies that use BMI as a measure of obesity. Oreopoulos et al. [8] suggested that BMI, as a surrogate for obesity, was better correlated with lean mass than body fat. Obesity indexed by BMI may sometimes indicate excessive muscle rather than excessive fat. Additionally, a previous study has suggested that lean mass, but not body fat, can predict all-cause death in patients with coronary artery disease [12]. Therefore, in the present study, we divided patients according to body compositions in order to accurately evaluate the influence of true obesity on the prognostic performance of NT-proBNP. Low NT-proBNP levels were observed in patients with high LMI, but not in those with high $\mathrm{BF}$, and the prognostic performance of NT-proBNP was significantly compromised in patients with high LMI and high BF. These findings suggest that it is not plausible to simply assume that low NT-proBNP levels reflect mild disease severity in obesity. In fact, early studies have suggested that BNP/NT-proBNP levels failed to reflect LV filling pressure in obese individuals, indicating that BNP/NT-proBNP should not be considered as a surrogate for disease severity in obese patients [33].

Obesity is typically accompanied with diabetes. There is growing evidence suggesting that low NP levels might play a role in the development of future diabetes [34]. In contrast, established diabetes has been shown to increase BNP/NTproBNP levels [35], which is partially attributed to diabetesassociated cardiac remodeling. Recent studies have shown that diabetes is an important extra-cardiac parameter that is associated with changes in BNP/NT-proBNP levels and that a high NT-proBNP level is a strong predictor of mortality in patients with diabetes $[35,36]$. Therefore, diabetes and body composition exert opposite effects on BNP and NT-proBNP changes, and the interpretation of NT-proBNP levels in diabetic and obese individuals is complicated. It is interesting to assess the influence of body composition on the NT-proBNP level and its prognostic performance in diabetic patients. Lunchner et al. [37] demonstrated that baseline established diabetes, but not BMI, was independently associated with changes in BNP/NT-proBNP levels 
during a 10-year follow-up. From a dynamic perspective, this finding indicates that the effect of longstanding diabetes on the BNP/NT-proBNP level will gradually become greater than the effect of body composition on the BNP/ NT-proBNP level, which is a plausible explanation for our finding that diabetes attenuated the influence of body composition on the NT-proBNP level and its prognostic value. Unfortunately, we were unable to accurately evaluate the effect of diabetes duration on NT-proBNP changes in obese individuals, as data on the diabetes duration were unavailable. Future studies are needed to address this issue.

The present study had several limitations. First, although this study focuses on the relationship between body composition and NT-proBNP levels, body fat and lean mass were not directly measured. Thus, further studies in which lean mass and body fat are directly measured using methods, such as dual-energy X-ray absorptiometry and bioelectrical impedance, are urgently needed. Nevertheless, the CUN-BAE equation has been derived from a large sample and validated in another large population. Meanwhile, as direct measurement of BF and lean mass is rarely applied in clinical practice, assessment of body composition using equations, such as the CUNBAE equation, probably reflects the situation in a routine clinical setting. Second, despite the large sample size, the present study was a single-center observational study. Therefore, confounding factors could not be entirely avoided. Third, potential selection bias might have been present, as this is an inherent limitation of real-world studies. However, considering the relatively large sample size, the results were not likely to be by chance. Forth, the number of diabetic patients was small, and this might have cause the insufficient results. Further studies in a larger population are needed to overcome this issue. Fifth, the study population mainly included Chinese individuals, and thus, we cannot extrapolate the findings to other races/ethnicities. A previous study reported that the NT-proBNP levels vary across different races [38].

\section{Conclusion}

In a large population of $>1600$ patients with ACS, we confirmed that BMI and LMI, but not BF amount, are inversely associated with NT-proBNP levels. Additionally, the prognostic performance of this biomarker may be compromised in patients with high BMI, LMI, or BF. The influence of body composition on the NT-proBNP level and its prognostic performance might be attenuated in diabetic patients with ACS.

\section{Abbreviations}

ACS: acute coronary syndrome; AMI: acute myocardial infarction; BF: body fat; BMI: body mass index; CAD: coronary artery disease; CKD-EPI: chronic kidney disease epidemiology; HR: hazard ratio; LMI: lean mass index; LVEF: left ventricular ejection fraction; LVEDV: left ventricular end-diastolic volume; NP: natriuretic peptide; NT-proBNP: N-terminal-pro B-type natriuretic peptide; TIMI: thrombolysis in myocardial infarction.

\section{Authors' contributions}

$\mathrm{FYH}$ had full access to all the data in the study and takes responsibility for the integrity of the data and the accuracy of the data analysis. MC, YZ, FYH, and HW participated in the conceptualization and design of the study. FYH, BTH, PJW, RSL, ZLZ, WL, and YP participated in the acquisition of data. FYH, BTH, $Z \mathrm{LZ}$, and $\mathrm{YH}$ participated in the analysis and interpretation of the data. $\mathrm{FYH}$, $H W, B T H, Y Y G$, and PJW participated in the drafting of the manuscript. MC, YZ, $Y P, T L X, C Z, X B P, S J C$, and WL carried out critical revision of the manuscript for important intellectual content. FYH, MC, and YZ participated in study supervision. All authors read and approved the final manuscript.

\section{Author details}

${ }^{1}$ Department of Cardiology, West China Hospital, Sichuan University, 37 Guoxue Street, Chengdu 610041, Sichuan, China. ${ }^{2}$ Department of Family Medicine, West China Hospital, Sichuan University, Chengdu, China.

\section{Acknowledgements}

The present study received Grants from the National Hightech Research and Development Program of China (Grant number: 2012AA02A510, Beijing, China), the National Natural Science Foundation of China (Grant Numbers: 81370219, Beijing, China), and the Supporting Project of Sichuan Provincial Department of Science and Technology (Grant Numbers: 2012FZ0065 and 2014SZ0004, Sichuan, China)

\section{Competing interests}

The authors declare that they have no competing interests.

Received: 15 January 2016 Accepted: 17 March 2016

Published online: 06 April 2016

\section{References}

1. Hou X, Lu J, Weng J, Ji L, Shan Z, Liu J, Tian H, Ji Q, Zhu D, Ge J, Lin L, Chen L, Guo X, Zhao Z, Li Q, Zhou Z, Shan G, Yang Z, Yang W, Jia W. Impact of waist circumference and body mass index on risk of cardiometabolic disorder and cardiovascular disease in Chinese adults: a national diabetes and metabolic disorders survey. PLoS One. 2013;8(3):e57319. doi:10.1371/ journal.pone.0057319.

2. de Lemos JA, Morrow DA, Bentley JH, Omland T, Sabatine MS, McCabe $\mathrm{CH}$, Hall C, Cannon CP, Braunwald E. The prognostic value of B-type natriuretic peptide in patients with acute coronary syndromes. N Engl J Med. 2001;345(14):1014-21. doi:10.1056/NEJMoa011053.

3. Morrow DA, de Lemos JA, Blazing MA, Sabatine MS, Murphy SA, Jarolim P, White HD, Fox KA, Califf RM, Braunwald E. Prognostic value of serial B-type natriuretic peptide testing during follow-up of patients with unstable coronary artery disease. JAMA. 2005;294(22):2866-71.

4. Wang TJ, Larson MG, Levy D, Benjamin EJ, Leip EP, Wilson PW, Vasan RS. Impact of obesity on plasma natriuretic peptide levels. Circulation. 2004;109(5):594-600. doi:10.1161/01.cir.0000112582.16683.ea.

5. Madamanchi C, Alhosaini H, Sumida A, Runge MS. Obesity and natriuretic peptides, BNP and NT-proBNP: mechanisms and diagnostic implications for heart failure. Int J Cardiol. 2014;176(3):611-7. doi:10.1016/j. ijcard.2014.08.007.

6. Lorgis L, Cottin Y, Danchin N, Mock L, Sicard P, Buffet P, L'Huillier I, Richard C, Beer JC, Touzery C, Gambert P, Zeller M. Impact of obesity on the prognostic value of the N-terminal pro-B-type natriuretic peptide (NT-proBNP) in patients with acute myocardial infarction. Heart. 2011;97(7):551-6. doi:10.1136/hrt.2010.213041

7. Choi SG, Jeong MH, Ahn Y, Cho JG, Kang JC, Chae SC, Hur SH, Hong TJ, Kim YJ, Seong IW, Chae JK, Rhew JY, Chae IH, Cho MC, Bae JH, Rha SW Kim CJ, Choi D, Jang YS, Yoon J, Chung WS, Seung KB, Park SJ. Relationship between obesity and $\mathrm{N}$-terminal brain natriuretic Peptide level as a prognostic value after acute myocardial infarction. Korean Circ J. 2010;40(11):558-64. doi:10.4070/kcj.2010.40.11.558. 
8. Oreopoulos A, Ezekowitz JA, McAlister FA, Kalantar-Zadeh K, Fonarow GC, Norris CM, Johnson JA, Padwal RS. Association between direct measures of body composition and prognostic factors in chronic heart failure. Mayo Clin Proc. 2010;85(7):609-17. doi:10.4065/mcp.2010.0103.

9. Lavie CJ, De Schutter A, Patel DA, Romero-Corral A, Artham SM, Milani RV. Body composition and survival in stable coronary heart disease: impact of lean mass index and body fat in the "obesity paradox". J Am Coll Cardiol. 2012;60(15):1374-80. doi:10.1016/j.jacc.2012.05.037.

10. Clerico A, Giannoni A, Vittorini S, Emdin M. The paradox of low BNP levels in obesity. Heart Fail Rev. 2012;17(1):81-96. doi:10.1007/ s10741-011-9249-z.

11. Das SR, Drazner MH, Dries DL, Vega GL, Stanek HG, Abdullah SM, Canham RM, Chung AK, Leonard D, Wians FH, de Lemos JA. Impact of body mass and body composition on circulating levels of natriuretic peptides: results from the Dallas Heart Study. Circulation. 2005;112(14):2163-8. doi:10.1161/circulationaha.105.555573.

12. Huang BT, Peng Y, Liu W, Zhang C, Huang FY, Wang PJ, Zuo ZL, Liao YB, Chai H, Huang KS, Huang DJ, Chen M. Lean mass index, body fat and survival in Chinese patients with coronary artery disease. QJM. 2015;108(8):641-7. doi:10.1093/qjmed/hcv013.

13. Gomez-Ambrosi J, Silva C, Galofre JC, Escalada J, Santos S, Millan D, Vila N, Ibanez P, Gil MJ, Valenti V, Rotellar F, Ramirez B, Salvador J, Fruhbeck G. Body mass index classification misses subjects with increased cardiometabolic risk factors related to elevated adiposity. Int J Obes. 2012;36(2):286-94. doi:10.1038/ijo.2011.100.

14. Gomez-Ambrosi J, Silva C, Catalan V, Rodriguez A, Galofre JC, Escalada J, Valenti V, Rotellar F, Romero S, Ramirez B, Salvador J, Fruhbeck G. Clinical usefulness of a new equation for estimating body fat. Diabetes Care. 2012;35(2):383-8. doi:10.2337/dc11-1334.

15. Grambsch PM, Therneau TM. Proportional hazards tests and diagnostics based on weighted residuals. Biometrika. 1994;81(3):515-26.

16. May S. Hosmer and Lemeshow type goodness-of-fit statistics for the Cox proportional hazards model Advances in survival analysis: handbook of statistics. Amsterdam: Elsevier; 2004. p. 383-94.

17. D'Agostino RB Sr, Grundy S, Sullivan LM, Wilson P. Validation of the Framingham coronary heart disease prediction scores: results of a multiple ethnic groups investigation. JAMA. 2001;286(2):180-7.

18. Sabatine MS, Morrow DA, de Lemos JA, Omland T, Desai MY, Tanasijevic $M$, Hall C, McCabe CH, Braunwald E. Acute changes in circulating natriuretic peptide levels in relation to myocardial ischemia. J Am Coll Cardiol. 2004;44(10):1988-95. doi:10.1016/j.jacc.2004.07.057.

19. Ndrepepa G, Braun S, Mehilli J, von Beckerath N, Vogt W, Schömig A, Kastrati A. Plasma levels of N-terminal pro-brain natriuretic peptide in patients with coronary artery disease and relation to clinical presentation, angiographic severity, and left ventricular ejection fraction. Am J Cardiol. 2005;95(5):553-7. doi:10.1016/j.amjcard.2004.10.034.

20. Ribeiro DG, Silva RP, Barboza DR, Lima-Junior RC, Ribeiro RA. Clinical correlation between $\mathrm{N}$-terminal pro-B-type natriuretic peptide and angiographic coronary atherosclerosis. Clinics (Sao Paulo). 2014;69(6):405-12.

21. Sakai H, Tsutamoto T, Ishikawa C, Tanaka T, Fujii M, Yamamoto T, Takashima $\mathrm{H}$, Horie M. Direct comparison of brain natriuretic peptide (BNP) and $\mathrm{N}$-terminal pro-BNP secretion and extent of coronary artery stenosis in patients with stable coronary artery disease. Circ J. 2007;71(4):499-505.

22. Riezebos RK, Laarman GJ, Tijssen JG, Verheugt FW. The value of N-terminal proB-type natriuretic peptide for early identification of myocardial infarction in patients with high-risk non-ST-elevation acute coronary syndromes. Clin Chem Lab Med. 2011:49(8):1359-65. doi:10.1515/CCLM.2011.213.

23. Lee JH, Park HS, Chae SC, Cho Y, Yang DH, Jeong MH, Kim YJ, Kim KS, Hur SH, Seong IW, Hong TJ, Cho MC, Kim CJ, Jun JE, Park WH. Predictors of six-month major adverse cardiac events in 30-day survivors after acute myocardial infarction (from the Korea Acute Myocardial Infarction Registry). Am J Cardiol. 2009;104(2):182-9. doi:10.1016/j. amjcard.2009.03.010.
24. Ranjith N, Pegoraro RJ, Naidoo DP, Esterhuizen TM. Prognostic value of $\mathrm{N}$-terminal-pro-brain natriuretic peptide measurements in patients with acute coronary syndromes. Cardiovasc J S Afr. 2006;17(2):60-6.

25. Gravning J, Smedsrud MK, Omland T, Eek C, Skulstad H, Aaberge L, Bendz B, Kjekshus J, Morkrid L, Edvardsen T. Sensitive troponin assays and $\mathrm{N}$-terminal pro-B-type natriuretic peptide in acute coronary syndrome: prediction of significant coronary lesions and long-term prognosis. Am Heart J. 2013;165(5):716-24. doi:10.1016/j.ahj.2013.02.008.

26. Sarzani R, Dessi-Fulgheri P, Paci VM, Espinosa E, Rappelli A. Expression of natriuretic peptide receptors in human adipose and other tissues. J Endocrinol Invest. 1996;19(9):581-5.

27. Sarzani R, Salvi F, Dessi-Fulgheri P, Rappelli A. Renin-angiotensin system, natriuretic peptides, obesity, metabolic syndrome, and hypertension: an integrated view in humans. J Hypertens. 2008;26(5):831-43. doi:10.1097/ HJH.0b013e3282f624a0.

28. Seferian KR, Tamm NN, Semenov AG, Tolstaya AA, Koshkina EV, Krasnoselsky MI, Postnikov AB, Serebryanaya DV, Apple FS, Murakami MM, Katrukha AG. Immunodetection of glycosylated NT-proBNP circulating in human blood. Clin Chem. 2008;54(5):866-73. doi:10.1373/clinchem.2007.100040.

29. Li CJ, Yu Q, Yu P, Yu TL, Zhang QM, Lu S, Yu DM. Changes in liraglutideinduced body composition are related to modifications in plasma cardiac natriuretic peptides levels in obese type 2 diabetic patients. Cardiovasc Diabetol. 2014;13:36. doi:10.1186/1475-2840-13-36.

30. Van Pelt RE, Gavin KM, Kohrt WM. Regulation of body composition and bioenergetics by estrogens. Endocrinol Metab Clin North Am. 2015;44(3):663-76. doi:10.1016/j.ecl.2015.05.011.

31. Chang AY, Abdullah SM, Jain T, Stanek HG, Das SR, McGuire DK, Auchus RJ, de Lemos JA. Associations among androgens, estrogens, and natriuretic peptides in young women: observations from the Dallas Heart Study. J Am Coll Cardiol. 2007;49(1):109-16. doi:10.1016/j.jacc.2006.10.040.

32. Won K-B, Hur S-H, Cho Y-K, Yoon H-J, Nam C-W, Kim K-B, Bae J-H, Choi D-J, Ahn Y-K, Park J-S, Kim H-S, Choi R-K, Choi D, Kim J-H, Han K-R, Park H-S, Choi S-Y, Yoon J-H, Kwon H-C, Rha S-U, Hwang K-K, Lim D-S, Jung K-T, Oh S-K, Lee J-H, Shin E-S, Kim K-S. Comparison of 2-year mortality according to obesity in stabilized patients with type 2 diabetes mellitus after acute myocardial infarction: results from the DIAMOND prospective cohort registry. Cardiovasc Diabetol. 2015;14(1):1-8. doi:10.1186/s12933-015-0305-1.

33. Taylor JA, Christenson RH, Rao K, Jorge M, Gottlieb SS. B-type natriuretic peptide and $\mathrm{N}$-terminal pro B-type natriuretic peptide are depressed in obesity despite higher left ventricular end diastolic pressures. Am Heart J. 2006;152(6):1071-6. doi:10.1016/j.ahj.2006.07.010.

34. Lazo M, Young JH, Brancati FL, Coresh J, Whelton S, Ndumele CE, Hoogeveen R, Ballantyne CM, Selvin E. NH2-terminal pro-brain natriuretic peptide and risk of diabetes. Diabetes. 2013;62(9):3189-93. doi:10.2337/db13-0478.

35. Gruden G, Landi A, Bruno G. Natriuretic peptides, heart, and adipose tissue: new findings and future developments for diabetes research. Diabetes Care. 2014;37(11):2899-908. doi:10.2337/dc14-0669.

36. von Scholten BJ, Reinhard H, Hansen TW, Lindhardt M, Petersen CL, Wiinberg $\mathrm{N}$, Hansen PR, Parving $\mathrm{H}-\mathrm{H}$, Jacobsen PK, Rossing P. Additive prognostic value of plasma $\mathrm{N}$-terminal pro-brain natriuretic peptide and coronary artery calcification for cardiovascular events and mortality in asymptomatic patients with type 2 diabetes. Cardiovasc Diabetol. 2015;14(1):1-10. doi:10.1186/s12933-015-0225-0.

37. Luchner A, Behrens G, Stritzke J, Markus M, Stark K, Peters A, Meisinger C, Leitzmann M, Hense HW, Schunkert H, Heid IM. Long-term pattern of brain natriuretic peptide and $\mathrm{N}$-terminal pro brain natriuretic peptide and its determinants in the general population: contribution of age, gender, and cardiac and extra-cardiac factors. Eur J Heart Fail. 2013;15(8):859-67. doi:10.1093/eurjhf/hft048

38. Gupta DK, de Lemos JA, Ayers CR, Berry JD, Wang TJ. Racial differences in natriuretic peptide levels: the Dallas Heart Study. JACC Heart Fail. 2015;3(7):513-9. doi:10.1016/j.jchf.2015.02.008. 